\title{
Rutas y flujo de recursos económicos entre Paraguay y Cuyo del reino de Chile (1580-1700)*/
}

\author{
Routes and the Flow of Economic Resources between \\ Paraguay and Cuyo of the Kingdom of Chile (1580-1700)
}

\author{
Margarita Gascón \\ ORCID iD: http://orcid.org/0000-0003-3448-0260 \\ INCIHUSA-CONICET, Argentina
}

Las primeras relaciones entre el corregimiento de Cuyo y Paraguay fueron un resultado de la estrategia defensiva de España. Durante el siglo XVII el comercio de vino y yerba mate consolidó la articulación de estas regiones. Basado en fuentes primarias y secundarias, el artículo subraya el rol de Santa Fe, puerto sobre el río Paraná, y analiza cómo el flujo de recursos relacionó Paraguay con Chile, vía el puerto de Santa Fe, Córdoba y Mendoza en Cuyo.

Palabras Clave: Mendoza; Chile; Santa Fe; Paraguay; Río Paraná; Vino; Yerba mate.

The first relationships between the Corregimiento of Cuyo and Paraguay were due to Spain's defensive strategy. During the seventeenth century, the commerce of wine and yerba mate consolidated the articulation of these regions. Based on primary and secondary sources, the article underlines the role of Santa Fe, a port by the Parana River, and analyzes how the flow of resources linked Paraguay with Chile, via the port of Santa Fe, Cordoba and Mendoza in Cuyo.

KeYwords: Mendoza; Chile; Santa Fe; Paraguay; Parana River; Wine; Yerba mate.

Copyright: ( 2017 CSIC. Este es un artículo de acceso abierto distribuido bajo los términos de una licencia de uso y distribución Creative Commons Attribution (CC-by) España 3.0.

* La investigación contó con ayuda financiera de CONICET-Argentina y se realizó en el marco del proyecto HAR2012-33784 entre la Universitat de Barcelona y el Ministerio de Ciencia e Innovación de España. 


\section{Introducción}

En este artículo proponemos que las primeras relaciones entre el corregimiento de Cuyo, en el reino de Chile, y Paraguay, vía Santa Fe, fueron el resultado del esquema para la defensa de principios del siglo XVII diseñado por España para el sur de su imperio en Hispanoamérica. Luego, fue el comercio de vino y yerba mate lo que, en la larga duración, consolidó la

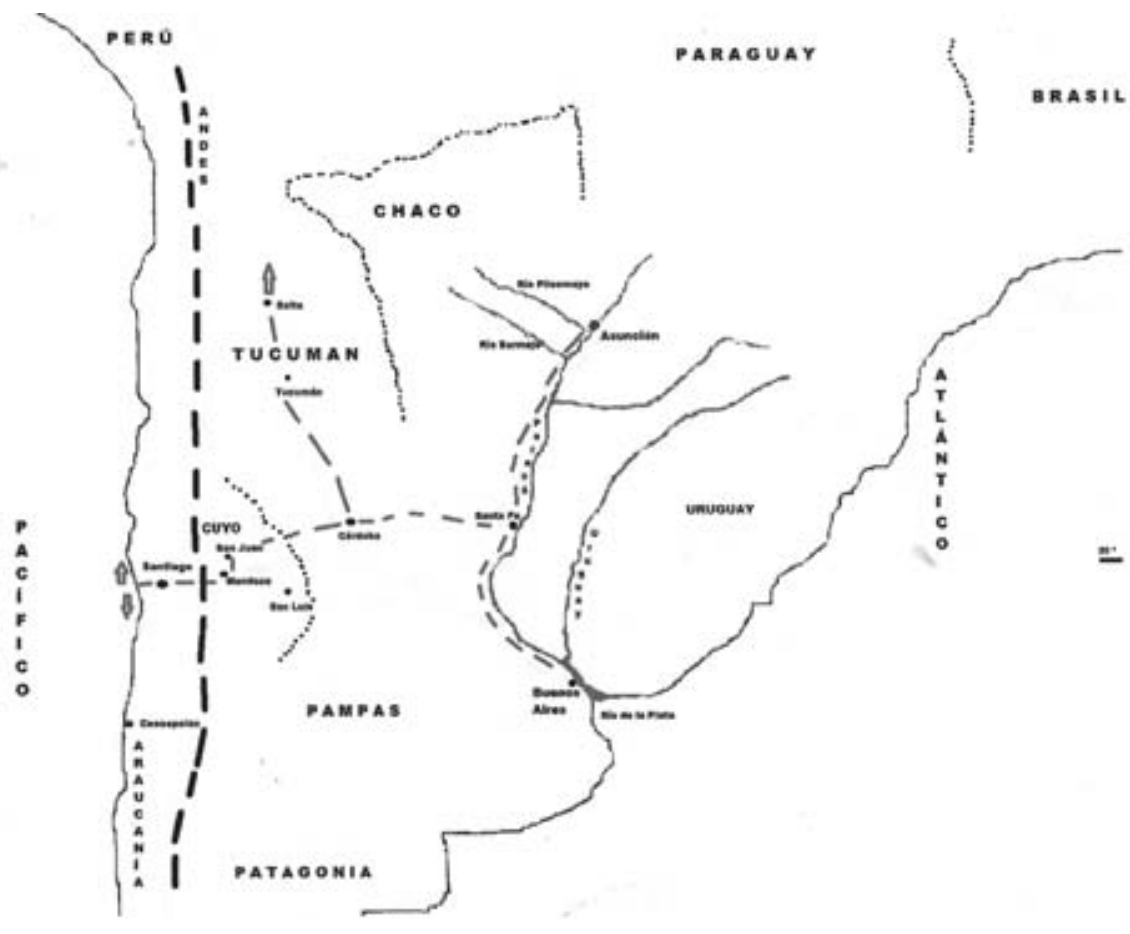

Ciudades y regiones coloniales.

articulación entre estas regiones. Analizamos un proceso que ha sido escasamente considerado en la historiografía en cuanto a cómo la organización para la protección de los territorios por parte de la corona fue el elemento inicial que vinculó a Paraguay y Chile, y cómo posteriormente el comercio consolidó esos vínculos. 
Como antecedente, el libro de Carlos Sempat Assadourian consideró las conexiones mercantiles interregionales, comenzando con la producción metalífera y siguiendo con la producción agraria. Su análisis reconstruyó, como él mismo señaló, la organización de los mercados internos, regiones y espacio económico. ${ }^{1}$ Sin embargo, Assadourian no profundizó en los vínculos entre Paraguay y Chile durante el siglo XVII, que es el núcleo de nuestro análisis. Además, como dijimos, subrayamos las causas y etapas iniciales de las relaciones entre ambos espacios. Señalamos que la causa fue, a fines del siglo XVI, la necesidad de proteger el sur de Hispanoamérica. Basado en fuentes primarias y secundarias, el artículo también muestra el rol de Santa Fe, un puerto sobre el río Paraná, y del comercio a través de él en la consolidación de los nexos entre el Paraguay con Chile, vía Mendoza en Cuyo.

En un mapa actual localizamos las colonias y regiones estudiadas. Para el periodo considerado, que se extiende entre 1580 y finales del siglo XVII, los límites inter-regionales eran difusos. Comencemos con algunas interpretaciones sobre cómo se representaban estos espacios en la cartografía colonial. ${ }^{2}$ Asunción del Paraguay y Santiago de Chile están alejados entre sí por unos 1.500 kilómetros lineales, incluyendo la navegación por el Paraná desde Asunción hasta el puerto de Santa Fe. Le seguía el tránsito por tierra hasta Córdoba $(360 \mathrm{~km})$, que dependía de condiciones meteorológicas favorables. Desde Córdoba, el ingreso a Mendoza en Cuyo se hacía por tramos donde predomina el clima desértico. Y ya en Mendoza había que organizar el cruce de los Andes por el paso de Uspallata, que está localizado a unos 2.000 metros sobre el nivel del mar. Atravesar la cordillera insumía otra semana completa del viaje y era posible solamente en los meses de verano.

Comenzaremos exponiendo los elementos ligados a la defensa imperial del sur de Hispanoamérica hacia el último tercio del siglo XVI, porque eso posibilitó el surgimiento del vínculo entre Chile y Paraguay. A finales del siglo XVI una revuelta masiva de araucanos expulsó a los españoles de las poblaciones ubicadas al sur del río Biobío, lo que fue trascendental porque cambió la evolución del Chile colonial en numerosos aspectos de su economía, sociedad y relaciones interétnicas. Desde nuestro punto de

\footnotetext{
1 Assadourian, 1982.

2 No interesa a los fines de este análisis discutir las características ni las limitaciones de los mapas históricos; sobre estos aspectos se pueden consultar Monmonier (1996), Harley (2005) y Lois (2006), entre otros.
} 
vista, fue trascendental ya que el sur chileno era una pieza fundamental para proteger al resto del virreinato del Perú. Dos décadas antes de la rebelión araucana, en 1578, la exitosa irrupción de Francis Drake en el Pacífico había probado el rol de Chile a la hora de cuidar las espaldas del virreinato y de preservar la integridad de la ruta del tesoro americano, desde Arica al Callao y desde allí a Panamá. La rebelión araucana de 1598-99 vulneraba la protección de los territorios y las rutas frente a probables invasiones ya que ahora los nativos rebeldes podían auxiliar a los enemigos de España. En consecuencia, una de las primeras medidas tomadas por España fue exigirles a los jesuitas el envío de guaraníes desde sus misiones paraguayas para auxiliar en la defensa de la Araucanía mientras se organizaba el envío de un ejército profesional desde la península. ${ }^{3}$ A esto le siguió el flujo de bienes paraguayos a través de una ruta que involucraba la navegación del río Paraná.

Este es, a grandes rasgos, el proceso que reconstruimos. Difiere del analizado para el puerto de Buenos Aires durante el siglo XVII por Zacarías Moutoukias. En el puerto bonaerense, activamente dedicado al contrabando, los intereses mercantiles de la élite y la política imperial para la protección del Río de la Plata fueron dos aspectos íntimamente relacionados y difíciles de separar, incluso analíticamente. ${ }^{4}$

\section{Política imperial y espacios coloniales}

Comencemos con las políticas defensivas imperiales para el sur del virreinato peruano y el momento inicial del proceso a finales de 1598, cuando los araucanos iniciaron una rebelión de tal magnitud que, tras la derrota de los españoles en Curalaba y el asesinato del gobernador Martín García Oñez de Loyola, los sobrevivientes debieron abandonar precipitadamente la Araucanía y refugiarse en la pequeña ciudad de La Concepción, en la ribera del Biobío. Mientras la junta de guerra ordenaba la organización de un ejército profesional de unas dos mil plazas, a pagar con un situado en las cajas peruanas, se ordenó a los jesuitas enviar guaraníes desde Paraguay para ayudar a la estabilización de la frontera interétnica en el sur de Chile. Cumpliendo con la orden, en 1608 alrededor de unos doscientos guaraníes llegaron a la Araucanía para servir en el ejército. A partir de esta fecha los

3 Gascón, 2011.

4 Moutoukias, 1988. 
jesuitas comenzaron a enviarles regularmente cargas de yerba mate y tabaco. La ruta tenía el río Paraná como eje navegable y utilizaba el puerto de Santa Fe, desde donde se llegaba a Córdoba por tierra. Desde Córdoba se ingresaba a Cuyo por San Juan de la Frontera y se seguía hacia el sur, para alcanzar Mendoza. Fundada en 1561, esta última ciudad era la capital del corregimiento de Cuyo, que pertenecía a Chile, y era donde se preparaba el cruce de los Andes.

Con el correr del siglo XVII, los productos paraguayos dejaron de ser exclusivamente para los guaraníes en la Araucanía, y su consumo se había expandido a lo largo de la ruta y en diversos sectores sociales, militares y civiles, españoles e indígenas. Los principales recursos del intercambio fueron el vino cuyano y la yerba mate paraguaya (ilex paraquariensis). Un ejemplo referido a Mendoza de cuán continuo y vigoroso fue este flujo es el juicio contra los jesuitas en 1696 debido a la denuncia de que los padres habían recibido una carga de yerba mate de 240 arrobas (una arroba equivalía aproximadamente a diez kilogramos) que se dirigía a Santiago de Chile. La denuncia era porque parte de esa yerba se vendía en el mercado local, aunque sin pagar los impuestos que sí pagaban los demás comerciantes. El rector del colegio se limitó a informar que esa yerba mate pasaba hacia Santiago para terminar en Lima, donde las ganancias le permitían a la Compañía adquirir ropas y esclavos. Agregó que la yerba mate que se vendía en Mendoza, junto con otros productos como pan y velas, «en el aposento de una negra», había sido recibida en pago por haberse vendido «en las provincias del Tucumán y Río de la Plata» los vinos y aguardientes que se elaboraban en las propiedades mendocinas de los jesuitas. ${ }^{5}$

Otros bienes fueron importados desde el Paraguay hacia la Araucanía debido a las necesidades del ejército de unas dos mil plazas, lo que tendría también repercusión en el proceso de articulación regional. ${ }^{6}$ Dado que los elementos para las campañas militares debían trasladarse a lomo de caballo o de mula, pues en la Araucanía no podían usarse carretas debido a sus senderos estrechos y ríos caudalosos, un informe militar aseguraba que se requerían de ocho a diez animales (entre mulas y caballos) por cada soldado en campaña. ${ }^{7}$ El obstáculo para abastecer de caballos al ejército era su

5 Denuncias contra la Compañía de Jesús, Mendoza, 1596, Archivo Histórico de Mendoza (AHM), Colonial, Eclesiástico, carpeta 278, documentos 58 y 60.

6 Gascón, 2000, 423-424.

7 La bibliografía sobre la frontera en la Araucanía colonial es extensa y variada; para ampliar referencias en relación con las actividades comerciales, ver Gascón, 2000, 447-448. 
escasez y elevado precio porque los civiles preferían la cría de mulas para las caravanas comerciales y porque, a diferencia de los caballos, las mulas casi nunca eran incautadas para el ejército. Importar los caballos desde el Paraguay se presentaba como la solución. ${ }^{8}$ Contamos con datos sobre este flujo de recursos gracias a un juicio contra un oficial encargado de realizar la compra de mil caballos para el ejército. En 1610 la misión recayó en el capitán Martínez de Zavala, quien volvió a Chile con solamente 158 animales que tampoco sirvieron para las actividades militares. En el juicio, Martínez de Zavala enunció los inconvenientes que lo exculpaban de delito alguno. ${ }^{9}$ Uno de ellos fue una crecida del Paraná, dijo, que le impidió llegar al Paraguay, de modo que compró los caballos a los criadores de Córdoba, quienes también estaban padeciendo por inclemencias climáticas. Cuando llegó a Mendoza en noviembre, todavía había temporales de nieve en los Andes: «con tantos meses cual jamás se han visto». ${ }^{10}$ Hoy sabemos que esos eventos meteorológicos anómalos fueron los efectos locales de un fenómeno de El Niño (ENOS - El Niño Oscilación del Sur). ${ }^{11}$

Para este flujo de recursos el Paraná era crucial. En los mapas coloniales se marcó la fuerte presencia de este río en el espacio. Inicialmente, el Paraná era considerado como el Río de Solís o Río de la Plata, constituyendo un gran sistema fluvial que conectaba Buenos Aires con el Alto Perú. De alguna manera se expresaba no tanto la realidad como el interés de los españoles por encontrar una conexión fluvial entre el frente Atlántico, con puerto en Buenos Aires, y el núcleo del virreinato, cuyo frente daba al $\mathrm{Pa}$ cífico en sus puertos de Valparaíso, Arica, Callao y Panamá. Este interés se relaciona con las necesidades defensivas pues, si existía semejante sistema fluvial, se podían enviar recursos bélicos al Alto Perú desde España, desembarcándolos en Buenos Aires. En otras palabras, se podía conectar el frente del Atlántico con el frente del Pacífico, evitando la peligrosa navegación del Estrecho de Magallanes.

El Nova et exacta delineatio Americae Partis Australis de Levinus Hulsuis, confeccionado en 1599, retrataba un posible sistema navegable

8 Gobierno de Juan de la Jaraquemada, Archivo Nacional de Chile (ANCh), Fondo Claudio Gay, tomo 14, expediente 27, doc. 24. Acta del 24 de enero de 1611, ANCh, Actas del Cabildo de Santiago de Chile, tomo X.

9 Juicio al capitán Pedro Martínez de Zavala, ANCh, Fondo Claudio Gay, exp. 22, tomo 14, doc. 24 .

10 Carta de Pedro Martínez de Zavala a SM, Tucumán, 24 de marzo de 1610, Biblioteca Nacional de Chile (BNCh), Sala Medina, Manuscritos, tomo 118, doc. 2085, 180-183.

11 Prieto y Richard, 1991. 
desde el Atlántico hasta el Alto Perú, a través del denominado «Río de la Plata o Paraná»..$^{12}$ Es interesante que su confección se relacione con la preocupación en la corte española por esta periferia austral. Para empezar, se sabía que existía una ruta terrestre desde la costa del actual Brasil hasta la actual Sucre (600 km al sur de Cusco), que había sido transitada por el portugués Alejo García en 1524 cuando, partiendo desde la isla de Santa Catarina $\left(27^{\circ} \mathrm{LS}\right)$, había llegado a Asunción del Paraguay. Aunque se desconoce su derrotero con exactitud, se cree que siguió un camino indígena denominado Peabiro. ${ }^{13}$ Aunque malograda, la expedición probaba la factibilidad de llegar hasta el Alto Perú desde la costa atlántica. Fue también una prueba de las penurias de semejante viaje y de la importancia de los nativos en cuanto a la logística y a tolerarles la mera presencia. Cuando García y sus hombres volvían con abundante plata, fueron asesinados por indígenas paraguayos. Desconociendo este final, una segunda expedición ya estaba en camino al saber de los buenos resultados iniciales de García y recién cuando llegaron a Paraguay supieron de la muerte de este y sus hombres. Los miembros de esta segunda expedición también se quedaron sin el apoyo de los nativos y fueron asesinados en una emboscada. ${ }^{14}$

A comienzos del siglo XVII, el mapa de Corneille Wytfliet daba una imagen de la cuenca del Río de Solís-Paraná como si permitiese llegar a sitios más al norte del trópico de Capricornio. Se trata del Plata Americae Provincia del atlas impreso en Lovaina en 1597, que señala las tempranas colonias de la malograda Sancti Spiritus (primera población fundada por Sebastián Gaboto en 1527 en actual territorio argentino), Córdoba, San Miguel (Tucumán) y Asunción. De manera similar, el mapa de Jodocus Hondius (Paraguay, o Prov. de Rio de la Plata cum regionibus adiacentibus Tvcvman et Sta. Cruz de la Sierra) marcó un sistema fluvial desde el Atlántico hasta el seno del continente sudamericano. ${ }^{15}$ En la corte española, el cronista de Indias Antonio de Herrera y Tordesillas (1549-1626) ponía en palabras esta noción de un vasto espacio donde el Paraná oficiaba de eje articulador, cuando sostenía que «este gran río de la Plata, por otro nombre

12 Los mapas mencionados están disponibles on line; el mapa de Hulsius puede verse, por ejemplo, en www.wdl.org/es/item/171/ y datos.bne.es/edicion/a4463246.html. Un importante repositorio es también www. memoriachilena.cl.

13 Rosas Moscoso, 2008, 115 y 159.

14 Roett y Sacks, 1991, 13. Charlevoix, 1910 [1756], I, 63-64.

15 Keuning, 1948. El mapa se puede consultar on line, por ejemplo en www.swaen.com/ jodocus-hondius-1629.php y www.raremaps.com/gallery/enlarge/35116. 
Paraguay [...] corre de las cordilleras del Perú y entra en la Mar del Norte [Atlántico] en altura de $35^{\circ}$ por el sur». ${ }^{16}$

Un detalle de interés del mapa de Hondius es que señala una ruta acompañando a un río (inexistente) que corre desde Mendoza hasta el sur de Buenos Aires. Al momento de confeccionarse este mapa, había pasado por Buenos Aires la expedición del general Alonso de Sotomayor que traía recursos desde España para el ejército de la Araucanía. Pero no es la ruta de Sotomayor la que está marcada pues este general ingresó a Cuyo por San Juan de la Frontera. Desde Buenos Aires, Sotomayor se había dirigido primero a Santa Fe y, desde allí, torció hacia el oeste para seguir a Córdoba. En Mendoza preparó el cruce de la cordillera. Esta ruta también se abrió ante las demandas imperiales de protección territorial porque Sotomayor había sido enviado como gobernador de Chile en la misma expedición que debía fortificar el Estrecho de Magallanes como respuesta a la expedición de Francis Drake. En 1578 después de atravesar el Estrecho en tiempo récord, Drake atacó al poderoso galeón español cargado del tesoro sudamericano poco antes de que este llegase a Panamá. Al conocerse esta noticia en España, la junta de guerra del Consejo de Indias ordenó reconocimientos costeros del sur de Chile junto con la colonización del Estrecho, enviando para ello a Pedro Sarmiento de Gamboa y a Alonso de Sotomayor como gobernador de Chile. ${ }^{17}$

Debido a varios inconvenientes durante la navegación (aunque una fuente argumenta problemas de salud entre sus hombres), ${ }^{18}$ Sotomayor decidió desembarcar en Buenos Aires y llegar a Chile por tierra, mientras que Sarmiento de Gamboa continuó hacia el Estrecho para efectuar las fortificaciones. Era 1580 cuando Sotomayor terminó de recorrer por primera vez la ruta completa que unía el puerto atlántico de Buenos Aires con Santiago de Chile, vía Mendoza. Sotomayor escribió a la corte sobre los beneficios de lo que él mismo denominó un «camino real» para la protección del sur del virreinato peruano, al posibilitar el envío de recursos militares desde la península ibérica, sin correr los riesgos de la navegación del Estrecho de Magallanes. ${ }^{19}$

La ruta entre Buenos Aires y Mendoza que figura en el mapa de Hondius seguía un curso de agua que nacía en las lagunas de Guanacache,

16 Herrera y Tordesillas, 1610, 196.

17 Sarmiento de Gamboa, 1894.

18 Servicios de Cristóbal González, Potosí, noviembre 2, 1592, documento reproducido en Anales de la Biblioteca de Buenos Aires, 10, 240-243, Newberry Library, Chicago, Illinois.

19 Caro de Torres, 1620. 
situadas entre San Juan y Mendoza, y desembocaba en el Atlántico al sur de Buenos Aires. Esta ruta (¿indígena tal vez?) marcaba el límite austral del mapa de Hondius del territorio «Paraguay o Provincia del Río de la Plata». Carecemos de pruebas documentales para corroborar si alguna ruta a esa latitud pudo haber sido recorrida por los españoles previamente a la elaboración del mapa, pero es seguro que no puede referirse a la ruta de Sotomayor. $^{20}$

Tres décadas más tarde, en 1657, quien fuera probablemente el más importante cartógrafo de su época, Nicolás Sansón (1600-1667), continuó representando al Río de la Plata y al río Paraná como parte de un mismo sistema fluvial que llegaba hasta la mitad de América del Sur. Otro siglo más y aun se dibujaba la desembocadura de los ríos de Mendoza en el Atlántico (lo que es erróneo) y se mantenía al Paraná como eje del sistema fluvial de mayor importancia en los territorios del noroeste argentino (lo que es correcto). ${ }^{21}$ Recordemos que una considerable parte de la cartografía se relacionó con los jesuitas, quienes habían fortalecido su red de circulación de bienes y personas entre sus colegios y misiones a lo largo del siglo XVII. ${ }^{22}$ Hasta que fueron expulsados en 1767, los jesuitas confeccionaron alrededor de 18 mapas sobre el Río de la Plata, la provincia de Tucumán, Paraguay y Chile. ${ }^{23}$ Sus representaciones e información nos importan ya que ellos fueron los primeros en activar el flujo de recursos económicos dentro del esquema para la protección de Chile en particular y del Perú en general. Asimismo, los jesuitas participaron en la consolidación de las relaciones entre Paraguay y Chile, vía Mendoza en Cuyo, al mantener los circuitos de intercambios entre sus estancias y colegios.

\section{Los flujos de yerba mate y vino en la articulación de los espacios coloniales}

Las caravanas que circularon desde temprano el siglo XVII entre Mendoza y Córdoba tenían como uno de sus destinos seguir hacia el puerto

20 Una copia apareció en el Atlas Novus de Willem y Joan Blaeu en 1635, que contenía 594 mapas; el titulado «Paraguay, o prov. de Rio de la Plata...» en www.wdl.org/es/item/1101/ [Consultado: 05/01/2016].

21 Forget y Bravard, 2011; y ark.digitalcommonwealth.org/ark:/50959/xg94j118s [Consultado: 03/12/2015].

22 Retz, 1732.

23 Furlong, 1961, 4, 193. 
de Santa Fe para vincularse con Paraguay navegando el Paraná. ${ }^{24}$ Se llevaban vinos y se traía yerba mate. Si bien estos no fueron los únicos bienes intercambiados entre Paraguay y Cuyo, sí fueron los principales y por ello son los que consideramos.

Paraguay era un neto proveedor de yerba mate, tabaco y ganado; y de maderas para la construcción de viviendas y embarcaciones. Los primeros relatos que así lo refieren son retratos de abundancia de recursos naturales y humanos con valor estratégico para las poblaciones. Fray Juan de Rivadeneyra, por ejemplo, describía en su «Relación de las provincias del Río de la Plata» $(1581)^{25}$ tres grandes ríos que desembocaban en el Río de la Plata, asegurando que se podían fundar tres ciudades y dar de comer a trescientos españoles dada la disponibilidad de peces, aguas, pastos y leña. No era menor su población nativa teniendo presente los requerimientos de mano de obra. Rivadeneyra hablaba de Asunción del Paraguay como un sitio de manufacturas destinadas a la producción y almacenaje de alimentos, y a su transporte por el río Paraná. Entre sus pobladores había toneleros, calafates, torneros, sogueros o cordoneros, carpinteros que hacen navíos, arcabuceros, herreros y plateros y demás oficios:

gran suma de labradores y muchos ingenios de azúcar, aunque ninguno hay fundado que muela de todos, sino que cada uno hace para sí su trapiche, y hay muchos que cogen a quinientas arrobas de miel de caña, que el año pasado se empezó a hacer Azúcar. Hay muchos vinos y frutas nuevas, mucho pan y tocino y vaca. ${ }^{26}$

Cuando Rivadeneyra escribió su obra, las necesidades de asegurar los confines australes del Perú debían ser conocidas porque, convenientemente, este fraile describía la utilidad de llegar desde Buenos Aires hasta Santa Fe navegando por el Paraná, para seguir a Chile vía Córdoba y entrando por San Juan de la Frontera. Desde San Juan, afirmaba, se podían cruzar los Andes y llegar al puerto de Coquimbo («La Serena de Coquimbo», en sus palabras), desde donde los refuerzos militares se podían llevar a cualquier otro puerto del Mar del Sur. Creemos que Rivadeneyra debió de tener noticias sobre este derrotero cuando lo propuso en una fecha tan temprana (1580) y vimos que, cuando llegó Sotomayor a Buenos Aires en 1583, se dirigió a Santa Fe

24 Archivo General de la Provincia de Santa Fe (ed.), 2003.

25 Archivo General de Indias, Patronato, 294, 14. PARES, Portal de Archivos Españoles, pares. mcu.es/ParesBusquedas/servlets/Control_servlet?accion=4\&appOrigen=ext\&txt_id_desc_ud=132598 [Consultado: 06/01/2016].

26 Citado por Campos Doria, 2010, 7. 
donde estaba Juan de Garay, su fundador y también el fundador de Buenos Aires por segunda vez. Garay proveyó a Sotomayor de caballos santafesinos para que continuase su ruta hacia Chile. ${ }^{27}$ Este dato importa porque en la descripción de Rivadeneyra sobre los beneficios militares de Santa Fe se resaltaba la abundancia de caballos en los alrededores de ese puerto y se aseguraba que servían para el traslado por tierra de hombres y bastimentos. ${ }^{28}$

Dado lo anterior, la descripción de este espacio hecha por Rivadeneyra puede relacionarse con el interés imperial de reducir la vulnerabilidad de zonas que podían ser ocupadas por enemigos europeos. Tras el ataque de Drake de 1579, vimos que se sucedieron medidas tales como el envío de Alonso de Sotomayor, quien desembarcó en Buenos Aires y fue efectivamente a Santa Fe. Desconocemos, sin embargo, si su intención era cruzar la cordillera por San Juan o por Mendoza. En los hechos, posteriormente al paso de Sotomayor, la ruta desde Buenos Aires a Santiago por Mendoza fue la más utilizada por militares, religiosos y civiles, contrabandistas y comerciantes. $^{29}$

La otra ruta para la circulación de los recursos era en sentido norte-sur y utilizaba al Paraná. Había llevado a la fundación de Santa Fe la Vieja en 1573 para que sirviese de puerto intermedio entre Asunción y Buenos Aires, y así figuró al definirse su jurisdicción: «por la parte del camino del Paraguay [...] y por el río abajo camino a Buenos Aires». Según Juan de Garay, Santa Fe contaba con «agua y leña y pastos y pesquerías, cazas y tierra y estancias para los vecinos y moradores de ella y repartirles como $\mathrm{Su}$ Majestad lo manda». ${ }^{30}$ No resultó, sin embargo, tentadora para los españoles, como lo atestigua su lento crecimiento demográfico. Incluso después de ser trasladada al sitio de la Vera Cruz, cuyo emplazamiento era mejor, según decían, pues evitaba las crecidas del río, las plagas de langostas y los ataques indígenas, Santa Fe estaba poco poblada. En 1621 Santa Fe la Vieja albergaba a 126 vecinos y moradores mientras que en 1675 en Santa Fe de la Vera Cruz había 270 vecinos. ${ }^{31}$

27 Gandía, 1961, 201.

28 Campos Doria, 2010, 6.

29 Moutoukias, 1998. Gascón, 2000. Gelman, 2006.

30 El acta de fundación del 15 de noviembre de 1573 está reproducida en los Libros del Cabildo con fecha del 19 de febrero de 1700, y publicada en Osuna, 1949. La necesidad de comunicar Asunción con Buenos Aires caracterizó las primeras décadas de la vida colonial (Gandía, 1935, 241322. Molas, 1868. Cervera, 1908. Cornero, 2010. Barriera, 2013).

31 Para el siglo XVII casi un treinta por ciento de sus pobladores eran portugueses, y estos tenían participación en cargos políticos (Areces y Tarragó, 1997. Areces, 2014). 
Para conectar el Paraguay con el circuito económico altoperuano y atlántico, Garay había partido de Santa Fe y fundado Buenos Aires por segunda vez en 1580. Según fray Reginaldo de Lizárraga ${ }^{32}$, Garay fue «a descubrir la tierra y ver si podía dar con la comarca de Tucumán, para comenzar a tener comercio con ella y con el Perú». Esto puso en marcha el resto del proceso poblacional y en 1585 Alonso de Vera y Aragón fundó Concepción del Bermejo y en 1588 Juan Torres de Vera y Aragón fundó San Juan de la Vera de las Siete Corrientes. ${ }^{33}$ Uno de esos espacios, el rioplatense, quedaba conectado con el noreste argentino y con el Paraguay, mientras que las relaciones con espacios al oeste (Cuyo y Chile) fueron quedando desdibujadas ante la creciente importancia de Buenos Aires en los circuitos comerciales.

En cuanto a la evolución que tuvieron los recursos intercambiados, hasta comienzos del siglo XVII, el principal producto paraguayo de exportación había sido el vino. Más tarde, la yerba mate se mantendría como el primer ítem, seguida por el azúcar (que siempre fue el segundo producto exportable) y el tabaco. Ya mencionamos cómo la primera etapa de la exportación a Chile se relacionó con el previo envío de guaraníes a la frontera sur. En un proceso de larga duración, los jesuitas primero y luego los civiles fueron abriendo mercados consumidores a lo largo de la ruta entre Asunción y la Araucanía. Vimos también que el Paraná permitía la circulación hasta el puerto de Santa Fe, desde donde se distribuían los bienes hacia el norte y el oeste. Al respecto, Garavaglia estimó que el flujo de yerba mate desde Paraguay a Santa Fe era de entre veinte mil y veinticinco mil arrobas anuales hacia fines del siglo XVII y primeras décadas del XVIII. ${ }^{34}$

Mendoza quedó en el circuito de la yerba mate al llevar «productos de la tierra» a Córdoba y Santa Fe, como permitía la corona. El argumentar que se llevaban vinos daba la posibilidad de desplazarse dentro de un sistema comercial restringido. Ese transporte de vinos a Santa Fe (donde incluso inicialmente competían con los vinos santafesinos y paraguayos), a pesar de ser costoso y arduo, dejaba ganancias porque se podían traer de vuelta yerba mate y otros productos. Incluso podían ser exportados a los mercados trasandinos y, cuando se cruzaba la yerba mate a Santiago, los

32 Lizárraga, 1916, II, 244.

33 Carrara y De Grandis, 2009.

34 Garavaglia, 2008, 90-93. 
mendocinos se unían al circuito comercial del Pacífico. ${ }^{35}$ En este circuito, la yerba mate pasaba por Mendoza y podía terminar en Buenos Aires, aunque sin haber llegado hasta allí navegando todo el curso del Paraná, sino a través de las cargas enviadas por los mercaderes limeños. Para comienzos del siglo XVIII y hasta mediados de esa centuria, Mendoza subió de tercero a segundo destino en importancia para la yerba mate comercializada en Santa Fe. ${ }^{36}$ Este dato no apunta al mercado consumidor mendocino, que era bastante reducido, sino a la posición de Mendoza en el amplio circuito referido arriba.

La competencia con los jesuitas por parte de los mendocinos que llevaban vinos para traer yerba mate era desigual. En el Paraguay y desde poco después de la instalación del colegio de la Compañía en 1609-1610, los padres retenían la comercialización de la yerba mate sin palo denominada caminí, que significa cultivada, que no ha sido sacada del monte o crecido salvaje. ${ }^{37}$ En el siglo XVIII la yerba mate del Paraguay preferida era la caminí y se consumía masivamente en todo el virreinato peruano. Fray Pedro José de Parras escribió sobre su consumo:

Los efectos de esta tierra son: primeramente la yerba que llaman del Paraguay, la cual es una hoja de un pequeño árbol, de que hay mucha abundancia por las cordilleras de Curuguaty, y en otras partes de esta jurisdicción, en distancia de sesenta, setenta y cien leguas de la Asunción. El uso de esta yerba, es ponerla en agua caliente, esto es, en la misma taza, y luego tomar dicha agua. Este es el regular desayuno en todo el reino del Perú, el que regularmente se repite muchas veces al día, y particularmente por la tarde, después de siesta. Para cuando se siente uno con demasiado calor, es una bebida singular, y especialmente para después de haber caminado un rato, en tiempo caluroso. Algunos usan tanto esta bebida, y en especial la gente de campo y de servicio, que pasan muchos años sin probar agua fría. ${ }^{38}$

Concluía que «casi toda la provincia del Paraguay subsiste por el comercio de la yerba, porque se gasta mucha en todo este reino, y no la hay en otra parte». Le aseguraban que la bebida curaba el denominado «mal de orina» en hombres (enfermedad de la próstata), aunque él conocía un

35 Las distancias desde Mendoza (línea recta, aproximadas) son: a Asunción del Paraguay, 1500 km; a Santa Fe, 800 km; a Córdoba, 500 km. A Santiago de Chile, la distancia en kilómetros no es grande, pero el cruce de los Andes tardaba una semana y se podía hacer solamente en los meses de verano.

36 Garavaglia, 2008, 94.

37 Molas, 1868, 63.

38 Parras, 1943, 211-212. 
caso donde el hecho de haber bebido mucho mate no le había evitado la enfermedad.

A su centralidad en las transacciones de productos paraguayos, Santa Fe sumó ser «puerto preciso» desde la segunda mitad del siglo XVII hasta 1779. Esto implicaba registrar productos, pago de impuestos y control del movimiento de los nativos que eran utilizados como peones para la navegación del Paraná. Se buscaba así evitar su desnaturalización: ${ }^{39}$

siendo una de sus causas principales del pedido por la Asunción, el que como los marineros que conducían las embarcaciones eran todos naturales de aquella provincia, con la mayor distancia de su país o por inclinación novedosa de los ánimos, no dejaran su natural residencia desamparando a sus mujeres e hijos. ${ }^{40}$

No solamente en la navegación sino también para cruzar el río, yendo de isla en isla, los indígenas eran necesarios ya que se usaba el denominado «peloteo», que era una especie de taza o «pelota» confeccionada con un cuero al pelo y plegado por sus bordes. Las estacas de madera aseguraban la abertura; una «pelota» puede verse en una ilustración del libro de Florián Paucke, donde se dibujó a un jesuita que cruza en una «pelota» conducida por un nativo nadando, mientras que otro nativo empuja una «pelota» desde la ribera hacia tierra firme. ${ }^{41}$

Los mendocinos favorecieron el comercio de vinos para llegar a Santa Fe donde se desembarcaban bienes paraguayos a lo largo del siglo XVII. En la centuria anterior, sin embargo, este comercio era despreciable pues todas las poblaciones procuraban tener sus viñas y producir sus vinos para consumo diario y por ser el vino necesario para oficiar las misas. El vino era además considerado una medicina y era una bebida segura, al menos más segura que el agua de las lagunas cuando se viajaba. Lo anterior explica que encontremos viñas incluso en lugares con climas poco propicios para su cultivo. ${ }^{42}$ En Paraguay, por ejemplo, había viñedos desde la fundación

39 Tedeschi, 2005, 10.

40 Cit. en Rivarola, 1986, sin paginar, nota 1346.

41 El mencionado dibujo del padre Paucke puede verse on line en varios lugares, y en Archivo General de la Provincia de Santa Fe (ed.), 2003, 44.

42 Hay que considerar la variabilidad climática, particularmente el fin del Calentamiento Medieval y el comienzo de una fase fría denominada Pequeña Edad Glacial, que se dio desde el siglo XV. La fase cálida previa desde el siglo X explica que, por ejemplo, en América del Norte, los europeos encontraran viñas salvajes en Nueva Inglaterra y más al norte incluso (la región denominada Vineland). No lo sabemos pero quizás inicialmente las condiciones climáticas fuesen propicias en Paraguay y Santa Fe para el arraigo de algunas variedades de vid (Wilcomb, 1971). 
de Asunción en 1537, y en 1571 López de Velasco afirmaba que «se coge mucho y buen vino». ${ }^{43}$ En 1589 fray Reginaldo de Lizárraga compró vino paraguayo para su viaje desde Córdoba a Chile, agregando que «traen de Santa Fe bonísimo vino, y de la Asumptión, porque como vienen el río abajo llegan en breve a Santa Fe». El relato muestra la dispersión del vino paraguayo una vez que llegaba al puerto de Santa Fe: «estando yo en Córdoba llegó allí un mercader con tres o cuatro carretas cargadas de vino bonísimo y conservas, y le compré dos arrobas para mi viaje de allí a Chile». ${ }^{44}$ En este sentido, la ruta del vino paraguayo precedió a la que seguiría después la yerba mate, su más emblemático producto.

En Santa Fe la Vieja también se plantaron viñedos al momento de su fundación, con poca suerte ya que un acta de cabildo anuncia que «no se dan las viñas por las hormigas y pulgones que acuden cada año». ${ }^{45}$ Eso no impidió, sin embargo, que se continuara con la elaboración de vino, aun si era de baja calidad, ya que permitía «estirar» los vinos mendocinos. Un ejemplo de estas prácticas podría ser Feliciano Rodríguez, vecinoencomendero, propietario local y en Buenos Aires. Dedicado al transporte fluvial de mercaderías por el Paraná, al morir en 1606, dejó 21 barriles, 20 botijas y tres cántaros de «vino de la tierra», a lo que se sumaban «treinta y cuatro ollas de hacer vino, una caldera grande de cobre y una alquitara o alambique para destilar alcohol del mosto» ${ }^{46}$ En varios testamentos encontramos referencias a viñas y botijas con «vino de la tierra» o bien con «vino de Chile» (casi seguro que se referiría al vino de Mendoza, capital del corregimiento de Cuyo que pertenecía a Chile). ${ }^{47}$ Las prácticas de adulteración eran tan frecuentes en Santa Fe que el fiel ejecutor y escribano de cabildo inspeccionaba dos veces por semana los sitios de venta de vino. Según se informaba, «con agua caliente mezclada con vinagre suelen, de una botija de vino bueno, hacer tres». ${ }^{48}$

Hasta 1626 la producción de vinos en Santa Fe fue considerada exitosa ya que en ese año el cabildo exigió que los vinos de otras regiones, especialmente los vinos mendocinos, se vendiesen después de acabado el vino elaborado localmente, y a más subido precio. Los mismos mecanismos se

43 Cit. por Cardozo, 1961, 168.

44 Lizárraga, 1916, II, 245.

45 Cit. por Roverano, 1983, 41.

46 Cit. por Areces y Tarragó, 1997.

47 Cervera, 1908, II, 71-73.

48 Cit., sin fecha, en Roverano, 1983, 69. 
utilizaron en ocasiones semejantes, como en Buenos Aires en 1612, cuando el cabildo protegió la producción local contra la introducción de vinos paraguayos. ${ }^{49}$

En Santa Fe, el aumento de impuestos a los vinos locales fue acusado de deteriorar los márgenes de ganancia y llevó a que el cabildo terminase por prohibir cortar cepas y vides porque recaudaba poco tributo en este rubro. Los gravámenes sobre el vino fueron importantes y le servirían al cabildo para financiar el traslado de Santa Fe al paraje de la Vera Cruz, algo que se concretó recién en $1660 .{ }^{50}$ A comienzos del siglo XVIII la producción de vinos en Santa Fe era mínima por lo que ahora sí el mercado era abastecido por vinos mendocinos. Lacoste afirma que anualmente desde Mendoza iban a Santa Fe treinta carretas con vinos, mientras que a Buenos Aires iba el doble. Los cálculos se han realizado sobre la producción total y se han basado en la cantidad de vides plantadas o en el número de botijas disponibles en los establecimientos elaboradores. Consideramos que tales cifras deben interpretarse como estimaciones y, por lo tanto, manejarse con prudencia. Por una parte, las cosechas suelen variar bastante de año en año ya que pudieron ser afectadas por situaciones impredecibles como eran las heladas, el granizo, los insectos y las enfermedades de las plantas. Por otra parte, la información documental para el siglo XVII es exigua e incompleta, dificultando establecer la evolución de la producción y comercialización. ${ }^{51}$ Según el padre Lozano, el deterioro en la producción tanto en Paraguay como en Santa Fe se debió a que las hormigas acabaron con las parras:

la multitud de hormigas persigue con tal tenacidad a los parrales que no deja llegar a sus frutos, por lo cual en el Paraguay desistieron de su cultivo y dejaron perder las muchos viñas que tenían plantadas y que fructificaron maravillosamente por muchos años, hasta que abundaron irresistiblemente estos insectos. ${ }^{52}$

Otro dato para interpretar con cuidado es que en 1680 se cobraban impuestos en Santa Fe a los vinos «de las provincias de Cuyo y Chile». ${ }^{53}$ No podemos saber cuán exacta es la separación territorial que ahora se hace al colocar esa «y» entre Cuyo y Chile. Creemos que más bien se refiere solamente a Mendoza, reconocida como el lugar por excelencia de origen

49 González Lebrero, 2002, 169-170.

50 Roverano, 1983, 90-92.

51 Lacoste, 2004, 62-93. Coria, 1988.

52 Lozano, 1873, 196-197.

53 Cervera, 1908, II, 7. 
de los vinos cuyanos: de Mendoza «sacan muy buen vino que llevan a Tucumán o de allá se lo vienen a comprar» ${ }^{54} \mathrm{y}$, en otro testimonio, el vino de Mendoza que se consume «no es muy inferior al de España». ${ }^{55}$ En 1679, bajo juramento, un particular había usado esa expresión de vino de «Cuyo y reino Chile», por lo que parece que era un uso de costumbre decir «Cuyo y reino Chile». Es difícil suponer que se podía cruzar los Andes con cargas de vino, y menos en carretas como se lee en una declaración: «dos carretas que traía de Cuyo y reino de Chile, una con 10 botijas de vino, 6 fardos de trigo y dos de aceite, que le pertenecían y traía para su casa». ${ }^{56}$

Por otra parte, el traslado en botijas de cerámica deterioraba los vinos, aunque cuando las caravanas se dirigían hacia el este, los vinos eran los «regalos» para los indígenas que ocasionalmente podían aparecer por el camino, de modo que la calidad era lo menos relevante si se los llevaba como «regalos». Por eso se colocaban botijas con los vinos de más baja calidad para cumplir con el pedido de los indios a cambio de no atacar a las caravanas. ${ }^{57} \mathrm{El}$ desprecio por la salud de quienes recibían de regalo vino que se encontraba en mal estado fue generalizado, y no se limitaba solamente a dárselo a los indígenas. En Santa Fe, el gobernador De la Cueva declaraba en sus ordenanzas para el comercio (1640) que se revisase el vino de las pulperías y que «sino [sic] es bueno, se regale a los conventos y pobres de la cárcel». ${ }^{58}$

\section{Conclusión}

Mostramos cómo en la última parte del siglo XVI las necesidades defensivas de España para el sur del virreinato del Perú iniciaron la articulación de dos espacios muy alejados entre sí como eran Paraguay y Chile. La respuesta de la corona a la expedición de Drake, la necesidad de proteger el Estrecho de Magallanes de incursiones de piratas y corsarios, la rebelión araucana de 1598 y el establecimiento de un ejército profesional en el sur de Chile fueron los momentos iniciales de este proceso. El envío de guaraníes desde las misiones paraguayas para ayudar en la estabilización

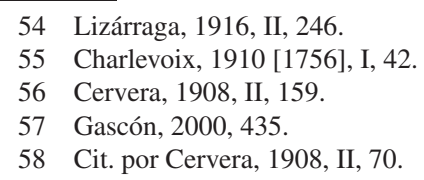


de la frontera después de la rebelión araucana sirvió para que los jesuitas comenzaran a enviarles yerba mate y tabaco; y ambos productos pasaban por Santa Fe, Córdoba y Mendoza. A eso se sumó la compra de caballos en Paraguay para el ejército.

En el mismo sentido referimos la apertura de la ruta entre Buenos Aires y Santiago de Chile que hizo Alonso de Sotomayor y la propuesta de fray Reginaldo de Lizárraga sobre el rol de Santa Fe en la vinculación entre aquellas dos ciudades. Consideramos datos que evidencian cómo fueron las primeras conexiones que se dieron en el marco de las necesidades de protección del espacio imperial. Y analizamos cómo durante el siglo XVII el flujo de bienes, principalmente vino y yerba mate, terminó de consolidar la articulación de estos espacios y las rutas dentro de amplios circuitos comerciales.

Recibido el 7 de abril de 2016

Segunda versión el 6 de septiembre de 2016

Aceptado el 29 de septiembre de 2016

\section{Referencias bibliográficas}

Archivo General de la Provincia de Santa Fe (ed.), Santa Fe, primera ciudad-puerto de la Argentina, Santa Fe, Bolsa de Comercio de Santa Fe, 2003, www.gramaestudio.com/bcsf/sfpcpdla.pdf [Consultado: 29/08/2015].

Areces, Nidia R., «Los registros arqueológicos e históricos y el caso de Santa Fe la Vieja», Revista TEFROS, 12, 2, 2014, Río Cuarto, 6-24, www.hum.unrc. edu.ar/ojs/index.php/tefros/article/view/287/268 [Consultado: 25/03/2015].

Areces, Nidia R. y Tarragó, Griselda B, «La élite santafesina en el siglo XVII. Familia y poder», Actas del $49 .^{\circ}$ Congreso Internacional de Americanistas, Quito, Ecuador, 1997, www.equiponaya.com.ar/congresos/contenido/49CAI/ Areces.htm [Consultado: 21/08/2015].

Assadourian, Carlos Sempat, El sistema de la economía colonial. Mercado interno, regiones y espacio económico, Lima, Instituto de Estudios Peruanos, 1982, repositorio.iep.org.pe/bitstream/IEP/239/1/estudioshistoricos10.pdf [Consultado: 01/09/2016].

Barriera, Darío, Abrir puertas a la Tierra. Microanálisis de la construcción de un espacio político. Santa Fe, 1573-1640, Santa Fe, Museo Histórico Provincial, 2013.

Campos Doria, Luis, Apuntes de Historia económica del Paraguay, Asunción, Intercontinental, 2010, www.portalguarani.com/...luis...campos_doria/ 15148_ apuntes_de_historia_economic [Consultado: 16/05/2015]. 
Cardozo, Efraím, «Asunción del Paraguay», en Levene, Ricardo (dir.), Historia de la Nación Argentina, Buenos Aires, El Ateneo 1961, 10 vols., III, 120-155.

Caro de Torres, Francisco, Relación de los servicios que hizo a su majestad el rey don Felipe Segundo y Tercero don Alonso de Sotomayor, Madrid, Impreso por la viuda de Cosme Delgado, 1620. [Consultado en The John Carter Brown Library, Providence, Rhode Island].

Carrara, María Teresa y De Grandis, Nélida, «El ordenamiento espacial en tiempos de Santa Fe la Vieja (1573-1660)», mns, 2009, www.icomos.org.ar/wp-con tent/uploads/2009/08/03_carrara_de_grandis.pdf [Consultado: 03/04/2015].

Cervera, Miguel de, Historia de la Ciudad y Provincia de Santa Fe, Santa Fe, La Unión. 1908, 2 vols., archive.org/details/historiadelaciu00cervgoo [Consultado: 17/07/2015].

Charlevoix, Pedro Francisco Javier de, Historia del Paraguay [1756], traducción de Pablo Hernández, Madrid, Victoriano Suárez, 1910, tomo I, archive.org/ details/historiadelparag00char [Consultado: 19/06/2015].

Coria, Luis, Evolución económica de Mendoza en la época colonial, Mendoza, Universidad Nacional de Cuyo, 1988.

Cornero, Silvia Elena (comp.), Pobladores de la Antigua Santa Fe del Quiloazas. Siglos XVI y XVII, Cayastá, Santa Fe, «Homenaje a Agustín Zapata Gollán y a los hombres que lo acompañaron en la excavación de la Vieja Santa Fe», Rosario - Cayastá, Consejo Federal de Inversiones - Editorial Ciudad Gótica, 2010, archive.org/details/2010PobladoresDeLaAntiguaStaFe [Consultado: 03/08/2015].

Forget, Marie Emilie y Bravard, Jean-Paul, «The role of historical sources in the functional representation of a river in the new world. The case of the Argentinian Paraná», Water History, 3, 2011, 227-249.

Furlong, Guillermo, «Cartografía Colonial», en Levene, Ricardo (dir.), Historia de la Nación Argentina, Buenos Aires, El Ateneo, 1961, 10 vols., IV, 175-202.

Gandía, Enrique de, «Jaime Rasquin y su expedición de 1559», Boletín del Instituto de Investigaciones Históricas, 18, Buenos Aires, 1935, 241-322.

Gandía, Enrique de, «La Segunda Fundación de Buenos Aires», en Levene, Ricardo (dir.), Historia de la Nación Argentina, Buenos Aires, El Ateneo, 1961, 10 vols, III, 181-204.

Garavaglia, Juan Carlos, Mercado interno y economía regional. Tres siglos de historia de la yerba mate, [México 1983], Rosario, Prohistoria, 2008.

Gascón, Margarita, «Comerciantes y redes mercantiles del siglo XVII en la frontera sur del Virreinato del Perú», Anuario de Estudios Americanos, 57, 2, Sevilla, 2000, 413-448.

Gascón, Margarita, Periferias imperiales y fronteras coloniales en Hispanoamérica, Buenos Aires, Dunken, 2011.

Gelman, Jorge (coord.), La Historia económica argentina en la encrucijada: balances y perspectivas, Buenos Aires, Prometeo, 2006. 
González Lebrero, Rodolfo, La pequeña aldea. Sociedad y economía en Buenos Aires (1550-1640), Buenos Aires, Biblos, 2002.

Harley, Brian, La nueva naturaleza de los mapas. Ensayos sobre la historia de la cartografía, México, Fondo de Cultura Económica, 2005.

Herrera y Tordesillas, Antonio de, Descripción de las Indias Occidentales, Madrid, Juan Flamenco, 1601, De Golyer Library, Southern Methodist University, Dallas, Texas.

Keuning, Johannes, «Jodocus Hondius Jr.», Imago Mundi, The International Journal for the History of Cartography, 5, 1948, 63-71.

Lacoste, Pablo, «La vid y el vino en América del Sur: el desplazamiento de los polos vitivinícolas (siglos XVI al XX)», Revista Universum, 19, 2, Talca, 2004, 62-93.

Lizárraga, Reginaldo de, Descripción breve del reino del Perú, Tucumán, Río de la Plata y Chile (1605), Buenos Aires, Librería La Facultad, 1916, 2 vols., www.cervantesvirtual.com/nd/ark:/59851/bmc0g3k3 [Consultado: 30/09/2015].

Lois, Carla (coord.), Imágenes y lenguajes cartográficos en las representaciones del espacio y del tiempo. I Simposio Iberoamericano de Historia de la Cartografía, Buenos Aires, Universidad de Buenos Aires, 2006, razoncarto grafica.files.wordpress.com/2007/08/i-simposio-iberoamericano-de-historiade-la-cartografc3ada-carla-lois-y-otros.pdf [Consultado: 05/07/2015].

Lozano, Pedro, Historia de la conquista del Paraguay, Río de la Plata y Tucumán, Buenos Aires, Imprenta Popular, 1873, archive.org/details/historiadelacon04 lozagoo [Consultado: 23/09/2015].

Molas, Mariano Antonio, Descripción histórica de la Antigua Provincia del Paraguay, Buenos Aires, Imprenta de Mayo, 1868, archive.org/details/descrip cionhisto00mola [Consultado: 22/05/2015].

Monmonier, Mark, Drawing the Line. Tales of Maps and the Cartocontroversy, New York, Holt and Co., 1996.

Moutoukias, Zacarías, Contrabando y control colonial, Buenos Aires, Centro Editor de América Latina, 1988.

Osuna, Aníbal, «Fragmento del Acta original de la Fundación de Santa Fe», Revista del Archivo Histórico de la Provincia de Santa Fe, 2, Santa Fe, 1949, 40-50.

Parras, Pedro José de, Diario y derrotero de sus viajes 1749-1753. España-Río de la Plata-Córdoba-Paraguay, Buenos Aires, Ediciones Solar, 1943, www.cer vantesvirtual.com/nd/ark:/59851/bmccc0z5 [Consultado: 26/10/2015].

Prieto, María del Rosario y Richard, Rodolfo «Anomalías climáticas en la Cuenca del Plata y NOA. Siglos XVI, XVII y XVIII», Leguas. Revista Argentina de Geografía, 1, Buenos Aires, 1991, 41-103.

Retz, Francisco, A Current Description of the Province of the Society of Jesus in Paraguay with Neighboring Areas, Roma, 1732, www.wdl.org/en/item/2581 [Consultado: 08/12/2015]. 
Rivarola Paoli, Juan Bautista, «El puerto preciso de Santa Fe», en Rivarola Paoli, Juan B., La economía colonial, Asunción, Editora Litocolor, 1986, 2. a parte, cap. IV, http://www.portalguarani.com/1067_juan_bautista_rivarola_paoli/ 12697_el_puerto_preciso_de_santa_fe__por_juan_bautista_rivarola_paoli. html [Consultado: 11/03/2015].

Roett, Riordian y Sacks, Richard, Paraguay: The Personalist Legacy, Boulder CO, Westview Press, 1991.

Rosas Moscoso, Fernando, Del Río de la Plata al Amazonas. El Perú y el Brasil en la época de la dominación ibérica, Lima, Editorial Universitaria-Universidad Ricardo Palma, 2008.

Roverano, Andrés, Santa Fe la Vieja, Santa Fe, Colmegna, 1983.

Sarmiento de Gamboa, Pedro, Narratives of the Voyages of Pedro Sarmiento de Gamboa to the Straits of Magellan, London, Hakluyt Society, 1895, https:// archive.org/details/narrativesofvoya00sarmrich [Consultado: 22/05/2015].

Tedeschi, Sonia, «La villa de Paraná y la ciudad de Santa Fe. Vínculos, Interacciones e influencias en un área fronteriza (etapa colonial hasta 1824)», mns, 2005, 1-29, http://cdn.fee.tche.br/jornadas/2/H4-17.pdf [Consultado: 22/05/2015].

Wilcomb, Washburn (ed.), Proceedings of the Vineland Map Conference, Chicago, University of Chicago Press, 1971. 